\title{
Effects of process changes on concentrations of individual malodorous sulphur compounds in ambient air near a Kraft pulp plant in Thunder Bay, Ontario, Canada
}

\author{
L. J. J. Catalan ${ }^{1}$, V. Liang ${ }^{1,2}$, C. Walton ${ }^{3}$ \& C. Q. Jia ${ }^{2}$ \\ ${ }^{1}$ Department of Chemical Engineering, Lakehead University, Canada \\ ${ }^{2}$ Department of Chemical Engineering and Applied Chemistry, \\ University of Toronto, Canada \\ ${ }_{3}^{3}$ Bowater Canadian Forest Products, Thunder Bay Operation, Canada
}

\begin{abstract}
Ambient air samples were collected at several locations in the community around a major Canadian pulp and paper plant over a period of several months, before and after major process changes. These changes, which occurred in the spring of 2006 , included the closure of one of two Kraft pulp mills on site and the shutting down of a chemical recovery boiler and associated black liquor oxidation systems. The facility currently operates one Kraft mill producing both hardwood and softwood market pulp and a two machine paper mill with thermomechanical and deinking pulp mills. All ambient air samples were collected downwind from the plant in Teflon bags and analyzed for volatile reduced sulphur compounds using a gas chromatograph equipped with a pulsed flame photometric detector and a cryogenic trapping system. The frequency distributions of the concentrations of hydrogen sulphide $\left(\mathrm{H}_{2} \mathrm{~S}\right)$, methyl mercaptan $\left(\mathrm{CH}_{3} \mathrm{SH}\right)$, dimethyl sulphide (DMS), and dimethyl disulphide (DMDS) were compared before and after the process changes. DMS was found to be the most abundant reduced sulphur compound in ambient air before the changes with an average concentration of $1.49 \mathrm{ppbv}$. After the changes, the average concentrations of $\mathrm{CH}_{3} \mathrm{SH}$, DMS, and DMDS decreased by 28,70 , and $58 \%$, respectively. The concentration of $\mathrm{H}_{2} \mathrm{~S}$ was below its detection limit of $0.90 \mathrm{ppbv}$ in most of the samples collected both before and after the process changes.

Keywords: reduced sulphur compounds, Kraft pulp mill, odour, pulsed flame photometric detector, gas chromatography, cryogenic trap, hydrogen sulphide, methyl mercaptan, dimethyl sulphide, dimethyl disulphide.
\end{abstract}




\section{Introduction}

The Bowater plant located in Thunder Bay, Ontario, Canada includes both newsprint and Kraft pulp manufacturing facilities. Before 3 May 2006, two Kraft pulp mills ("A" mill and "B" mill) produced a combination of hardwood and softwood elemental chlorine free bleached market pulp. The chemical recovery process utilized two recovery boilers ("B" and " $C$ ") and two lime kilns (" $A$ " and "B"). On 3 May 2006, the "A" Kraft mill, which included the "B" recovery boiler and the "A" lime kiln, was shut down.

Since 1994, the plant has invested in several air improvement initiatives to reduce total reduced sulphur (TRS) and particulate emissions, including:

i. installation of scrubbers and electrostatic precipitators on the bark boilers (1994/1996),

ii. improvements to the "B" Recovery Boiler (1995/99/02),

iii. upgrades to the bleach and chemical plant scrubbers (2001/03),

iv. removal of the old " $A$ " recovery boiler (2001),

v. construction of new low odour "C" recovery boiler utilizing 3 levels of combustion air to ensure complete combustion of the black liquor and a non-contact evaporation system to evaporate water from the liquor prior to burning (2001),

vi. discontinuation of weak black liquor oxidation system (2003) and replacement with a total heat recovery (THR) system where pure oxygen is used to more efficiently converting the sulfide in black liquor to thiosulfate and thus raise the heating value of the black liquor prior to burning in the recovery boiler,

vii. replacement of wet scrubbers on the "A" and "B" lime kilns with electrostatic precipitators (2004), and

viii. installation of a dilute non-condensable gas (DNCG) system to collect, concentrate, and incinerate reduced sulfur gases emitted from roof top tank vents and chip bin exhausts (2004).

Four reduced sulfur compounds, i.e. hydrogen sulfide $\left(\mathrm{H}_{2} \mathrm{~S}\right)$, methyl mercaptan $\left(\mathrm{CH}_{3} \mathrm{SH}\right)$, dimethyl sulfide (DMS), and dimethyl disulfide (DMDS) emitted from kraft pulp mills are mainly responsible for odour problems. These compounds are collectively designated as Total Reduced Sulphur (TRS). The odour threshold for TRS compounds are very low: $0.41 \mathrm{ppbv}$ for $\mathrm{H}_{2} \mathrm{~S}, 0.07 \mathrm{ppbv}$ for $\mathrm{CH}_{3} \mathrm{SH}, 3.0 \mathrm{ppbv}$ for DMS, and $2.2 \mathrm{ppbv}$ for DMDS, where ppbv refers to parts per billion on a volume basis [1].

The TRS concentration is defined as the sum of the sulphur contributions from the four individual TRS compounds:

$$
C_{T R S}=C_{H_{2} S}+C_{C H_{3} S H}+C_{D M S}+2 C_{D M D S}
$$

where $\mathrm{C}$ refers to concentration on a volume or molar basis. Under the ambient air quality criteria (AAQC) in Ontario, the limit on 1-hour average TRS concentration is $40 \mathrm{mg} / \mathrm{m}^{3}$ as $\mathrm{H}_{2} \mathrm{~S}$ [2], which corresponds to a TRS volume concentration of 27 ppbv. TRS compounds normally present no health hazard to humans, except at very high concentrations. 
The determination of reduced sulphur compounds is complicated by their high reactivity, which can result in severe losses during sampling and analysis. The materials that come in contact with the samples must be inert toward sulphur compounds to minimize these losses.

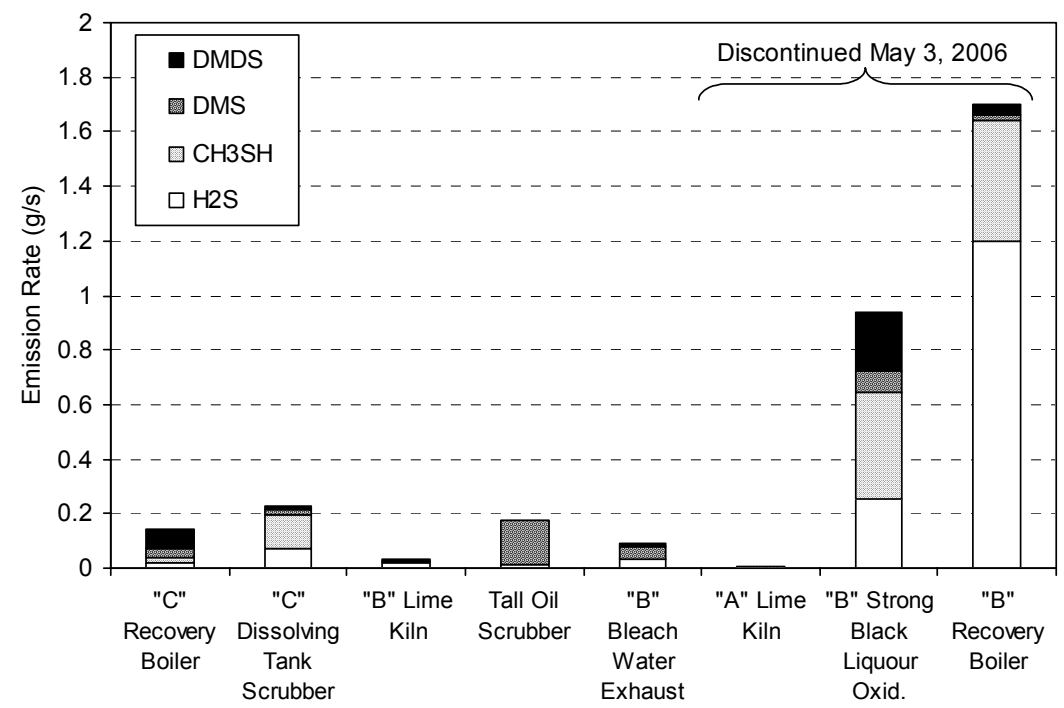

Figure 1: $\quad$ Summary of main TRS sources for Bowater facilities [3].

Table 1: Annual emissions of TRS compounds for the entire Bowater plant.

\begin{tabular}{lcccc}
\hline & $\mathrm{H}_{2} \mathrm{~S}$ & $\mathrm{CH}_{3} \mathrm{SH}$ & DMS & DMDS \\
\hline Emissions (kg/yr) & & & & \\
- Before 3 May 2006 & 47,939 & 29,478 & 6,262 & 10,999 \\
- After 3 May 2006 & 4,351 & 4,422 & 3,359 & 3,039 \\
Percent Reduction & $91 \%$ & $85 \%$ & $46 \%$ & $72 \%$ \\
\hline
\end{tabular}

\subsection{TRS emissions inventory}

Figure 1 shows the emission rates of TRS compounds in $\mathrm{g} / \mathrm{s}$ from the major individual point sources at the Bowater plant measured in September 2005 [3]. All sources operate between 94 and $98 \%$ of the time, except for the tall oil scrubber, which only emits $8 \%$ of the time. The "B" Recovery Boiler and the B Strong Black Liquor oxidation unit were by far the largest sources of TRS compounds before 3 May 2006. However, these sources were discontinued with 
the shut-down of the "A" Kraft mill on 3 May 2006. Annual emissions of TRS compounds in $\mathrm{kg} / \mathrm{year}$ for the entire plant before and after 3 May 2006 are reported in Table 1. The operating times of each source were taken into account to calculate annual emissions. The emissions of $\mathrm{H}_{2} \mathrm{~S}$ and $\mathrm{CH}_{3} \mathrm{SH}$ were the most affected by the closure of the "A" Kraft mill, with reductions of $90.9 \%$ and $85 \%$, respectively. Emissions of DMS and DMDS were also reduced by 46.4 and $72.4 \%$, respectively.

\subsection{Objectives}

This paper reports the results of analysis of TRS compounds in ambient air samples collected before and after 3 May 2006 downwind of the plant main stack. The effects of the "A" Kraft mill shutdown on the concentrations of individual TRS compounds in ambient air are quantified. The changes in ambient air concentrations are then compared with changes in TRS emission rates from the plant.

\section{Methods}

\subsection{Air sampling methods}

Ambient air samples were collected in the community surrounding the Bowater plant outside the plant boundaries from 5 April to 14 September 2006. Before the shutdown of the "A" Kraft mill, a total of 18 samples were collected on 9 different days between 5 April and 2 May 2006. After the shutdown of the "A" Kraft mill, 39 samples were collected on 21 different days between 23 May and 14 September 2006. On each sampling date, the sampling location was selected to be downwind from the plant main stack. All the sampling was done within a $2-\mathrm{km}$ radius from the plant. Figure 2 shows a map of the 10 sampling locations that were used around the Bowater plant.

A schematic of the air sampling apparatus is shown in Figure 3. Ambient air is drawn through a 1/4-in OD Teflon sampling tube whose inlet is held at $2 \mathrm{~m}$ above the ground by pole mounted on a tripod. The Teflon tube is connected to one side of a Teflon port inserted through the wall of a 1450 Pelican case (Pelican Products, Torrance, California) having interior dimensions of $37.1 \times 25.8 \times 15.2 \mathrm{~cm}$. The other side of the Teflon port is connected to a $2 \mathrm{~L}$ $(23 \mathrm{~cm} \times 23 \mathrm{~cm})$ Teflon bag (Chromatographic Specialties, Brockville, Ontario) held inside the Pelican case. A second port on the Pelican case allows for connection to an SKC 224-44XR air-sampling pump (SKC Inc., Eighty Four, Pennsylvania) via Tygon tubing. Because the Pelican case is airtight, drawing air from the interior of the pelican case with the air sampling pump causes the Teflon bag to fill with ambient air drawn through the Teflon sampling tube. This set-up ensures that the sampled air only comes in contact with Teflon, which is inert towards reduced sulphur compounds. Each air sample was collected within a period of $4 \mathrm{~min}$ at a rate of $450 \mathrm{~mL} / \mathrm{min}$. 


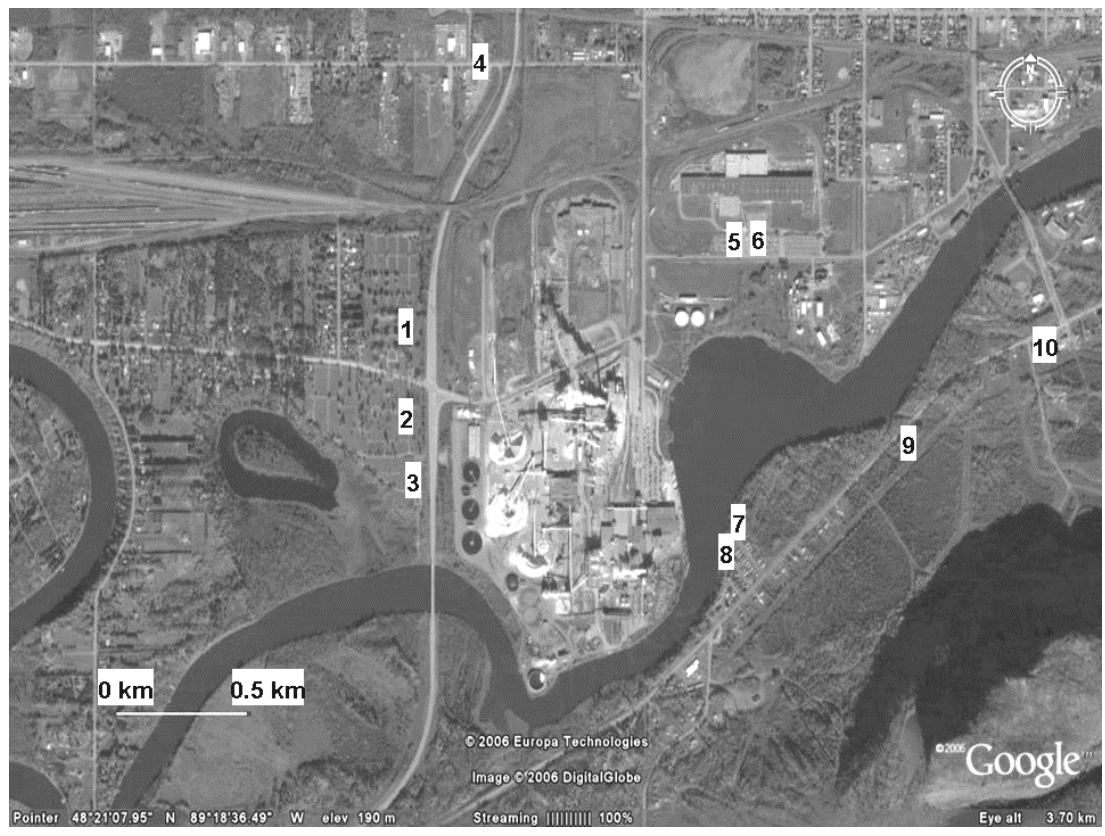

Figure 2: Aerial photograph of the Bowater plant and sampling locations.

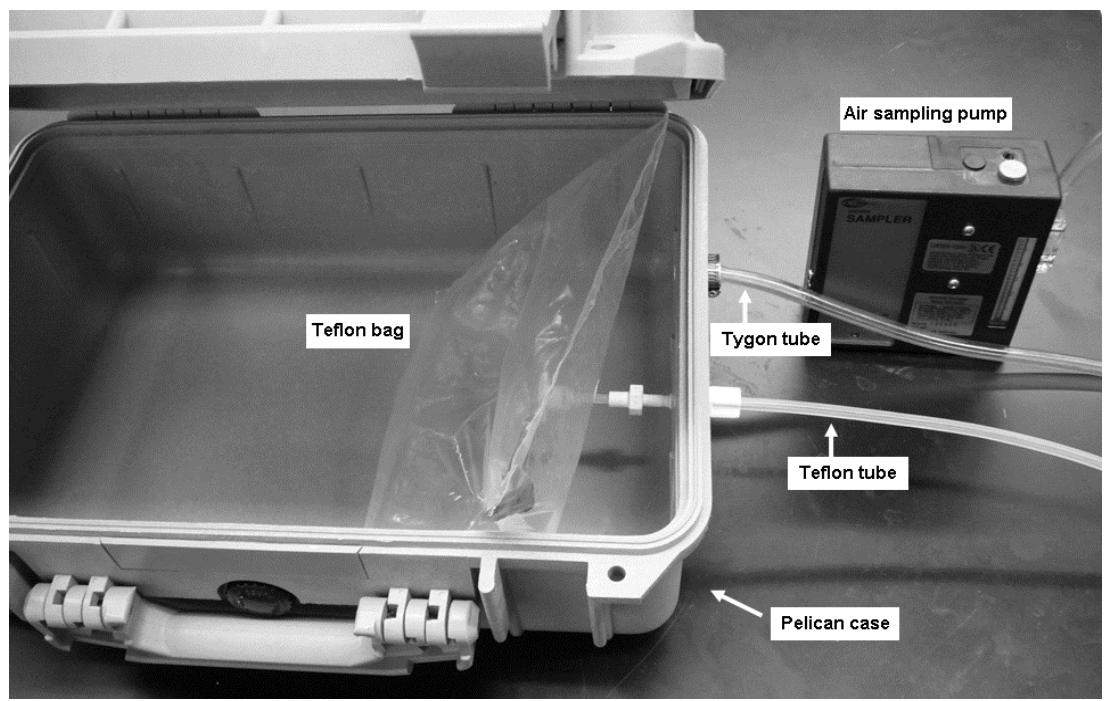

Figure 3: Schematic of air sampling apparatus. 
During sampling, a portable meteorological station (Signal Weather Services, Dryden, Ontario) was used to monitor the wind speed, wind direction, temperature, and relative humidity at 1-minute intervals. Once an ambient air sample is collected, the Pelican case is opened, the valve of the Teflon sampling bag is closed, the bag is removed, and a new bag is installed for collecting the next air sample. After collection, the air samples were stored in an insulated cooler bag with cold packs for transportation to the laboratory. Upon arrival in the laboratory, the samples were transferred to a fridge and analyzed within 2 to 3 hours after collection. To minimize sampling costs, Teflon bags were re-used after flushing at least three times with ultra-high purity nitrogen gas. Tests were carried out to ensure that re-used bags did not introduce contamination in the new samples.

\subsection{Analytical methods}

The ambient air samples were analyzed by a trace level sulphur analyzer consisting of a gas chromatograph (Varian CP 3800, Palo Alto, California) equipped with a pulsed flame photometric detector (PFPD) and interfaced with a cryogenic trap (Lotus Consulting, Long Beach, California) for pre-concentration of ambient samples. Air samples were introduced in the Lotus preconcentrator by connecting the valve of the Teflon bag to the inlet port of the preconcentrator with a Teflon fitting. A mass flow controller located downstream of the cryogenic trap controlled the flow rate at which air was removed from the bag. For each analysis, a total volume of $210 \mathrm{~mL}$ of ambient air flowed through the trap. All the tubing that comes into contact with the air sample in the analytical equipment is treated with a silcosteel ${ }^{\mathrm{TM}}$ coating (Restek Corporation, Bellefonte, Pennsylvania) to prevent adsorption of active sulphur compounds. Details of the analytical system and calibration procedures can be found in Catalan [4]. The calibration was repeated every two weeks to ensure accuracy of the analytical results. The absolute instrument sensitivity (AIS) was determined to be 0.90 ppbv for $\mathrm{H}_{2} \mathrm{~S}, 0.51 \mathrm{ppbv}$ for $\mathrm{CH}_{3} \mathrm{SH}, 0.092 \mathrm{ppbv}$ for DMS, and $0.009 \mathrm{ppbv}$ for DMDS. The AIS is a reliable and conservative measure of detection limit for volatile sulphur compounds by GC-PFPD [5].

The stability of reduced sulphur compounds in the Teflon sampling bags was assessed by introducing a gas mixture containing 2.1 ppbv $\mathrm{H}_{2} \mathrm{~S}, 4.7 \mathrm{ppbv}$ $\mathrm{CH}_{3} \mathrm{SH}, 1.5 \mathrm{ppbv}$ DMS, and $1.0 \mathrm{ppbv}$ DMDS in a clean Teflon bag and then periodically withdrawing aliquots which were analyzed to monitor the changes in concentration with time. These initial concentrations were representative of concentrations measured in actual ambient air samples. Figure 4 shows the composition of the gas mixture as a function of time. Any change from the initial concentration is due to decomposition of TRS compounds in the gas phase or adsorption on the bag walls. The concentrations of all the TRS compounds remained within $10 \%$ of the initial concentrations for at least 3 hours after the Teflon bag was filled. $\mathrm{CH}_{3} \mathrm{SH}$ exhibited the largest losses $(-7 \%$ after 2.7 hours and $-20 \%$ after 3.8 hours). By contrast, the concentration of DMDS was found to remain constant for more than 7 hours. Similar results were obtained when the initial concentrations were doubled. These results indicate that no significant 
losses of TRS compounds from ambient air samples can be expected during the time that separated sample collection from analysis $(<3$ hours).

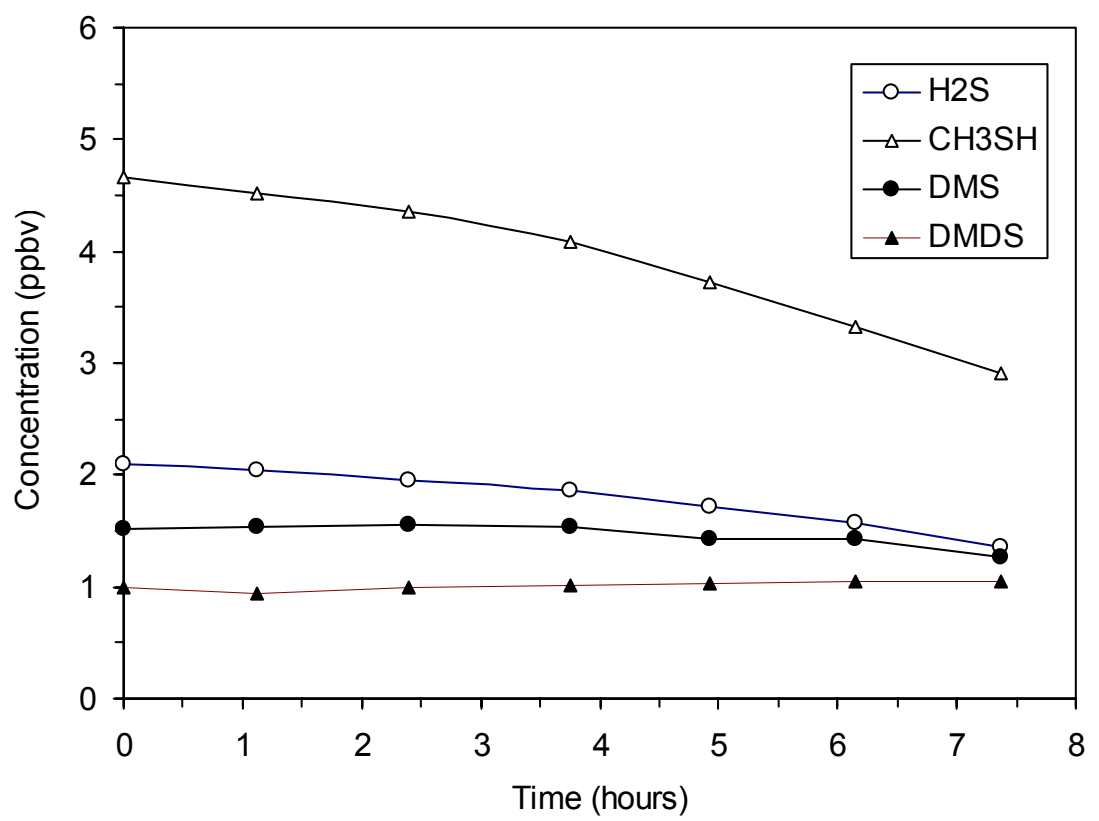

Figure 4: $\quad$ Stability of TRS compounds in Teflon sampling bag.

\section{Results and discussion}

Figures 5(a)-(d) show the frequency distributions of the concentrations of DMDS, DMS, $\mathrm{CH}_{3} \mathrm{SH}$, and $\mathrm{H}_{2} \mathrm{~S}$, respectively. For each compound, two distributions corresponding to the data taken respectively before and after 3 May 2006 are shown. The $x$-axis represents the frequency of ambient air samples having a concentration greater than the stated values. For example, Figure 5(b) shows that $59 \%$ of the samples collected before 3 May 2006 had a DMS concentration greater than 1 ppbv, whereas only $12 \%$ of the samples collected after that date had a DMS concentration greater than 1 ppbv. Frequency distributions for DMS and DMDS concentrations consistently shifted toward lower concentrations after 3 May 2006 (Figures 5(a) and 5(b)), thus demonstrating the beneficial effect of the "A" Kraft mill shutdown on concentrations of DMS and DMDS in ambient air.

The frequency distributions for $\mathrm{CH}_{3} \mathrm{SH}$ concentrations (Figure 5(c)) contain much fewer data points than those for DMS and DMDS. This is because $\mathrm{CH}_{3} \mathrm{SH}$ was below the detection limit in most of the ambient air samples. Before 3 May $2006, \mathrm{CH}_{3} \mathrm{SH}$ was detected in only $35 \%$ of the samples. After that date, $\mathrm{CH}_{3} \mathrm{SH}$ was detected in only one sample out of 39 samples. On the single occasion when 
(a)

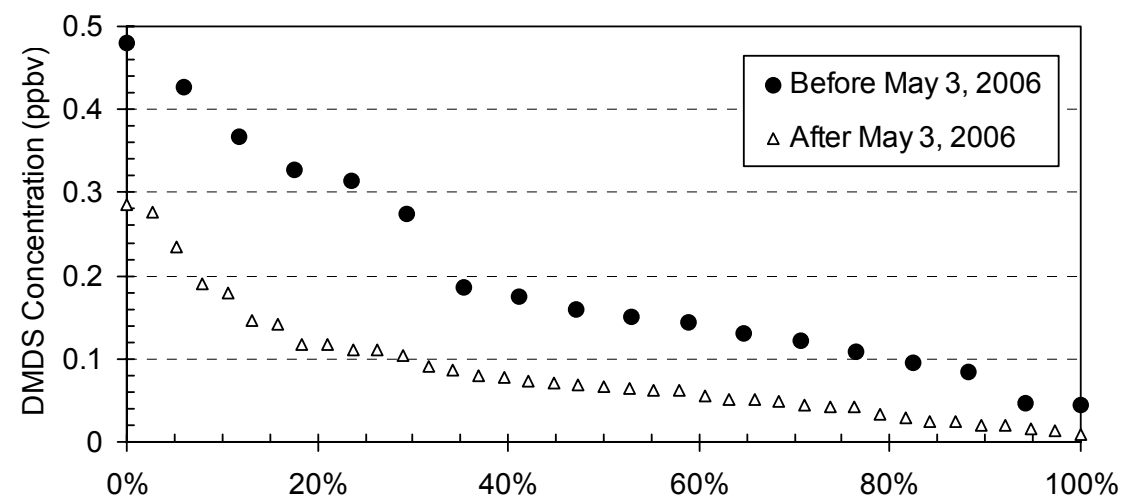

(b)

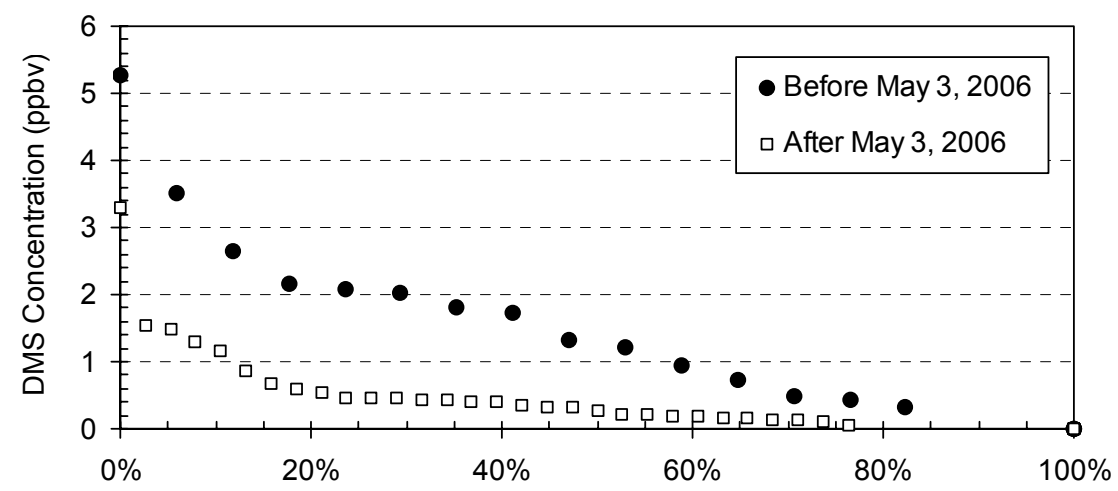

(c)

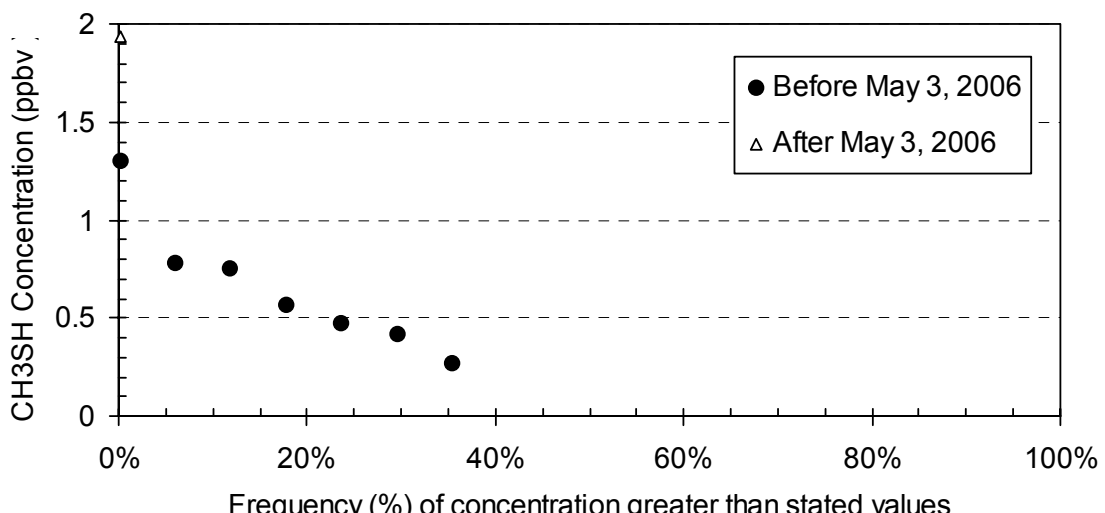

Figure 5: Frequency distributions of (a) DMDS, (b) DMS and (c) $\mathrm{CH}_{3} \mathrm{SH}$ concentrations in ambient air samples. 
(d)

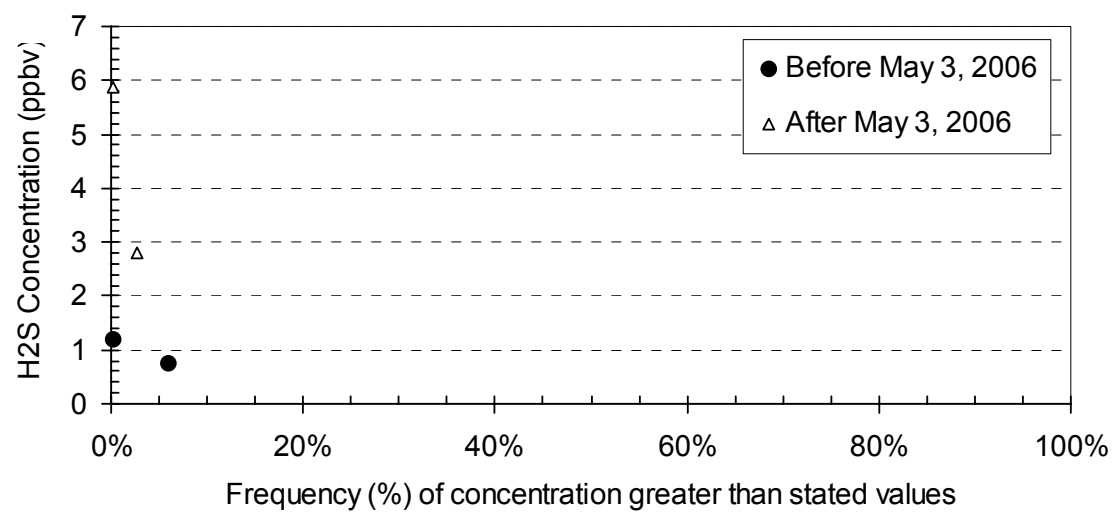

Figure 5 (cont'd): Frequency distributions of (d) $\mathrm{H}_{2} \mathrm{~S}$ concentrations in ambient air samples.

$\mathrm{CH}_{3} \mathrm{SH}$ was detected (30 August at 2:21pm), its concentration was the highest that was recorded in the entire sampling campaign (1.94 ppbv). Overall, the "A" Kraft mill shutdown resulted in a large decrease in the frequency of detectable $\mathrm{CH}_{3} \mathrm{SH}$ concentrations in ambient air samples. It is worth noting that on three occasions before 3 May 2006, $\mathrm{CH}_{3} \mathrm{SH}$ was detected and quantified at levels below the reported absolute instrument sensitivity of $0.51 \mathrm{ppbv}$. This is because the AIS is calculated using an average root mean square (rms) noise evaluated over several chromatograms [5], whereas the actual rms noise for a particular chromatogram can be lower than the average rms noise, thus allowing measurement of the analyte below the reported AIS.

The frequency distributions for $\mathrm{H}_{2} \mathrm{~S}$ concentrations indicate that $\mathrm{H}_{2} \mathrm{~S}$ was only detected in two samples before and after 3 May 2006 (Figure 5(d)). On the two occasions when $\mathrm{H}_{2} \mathrm{~S}$ was detected after 3 May 2006, the $\mathrm{H}_{2} \mathrm{~S}$ concentrations $(2.8$ and $5.9 \mathrm{ppbv}$ on 20 June at $3: 52 \mathrm{pm}$ and 30 August at 2:21 pm, respectively) were higher than concentrations detected before 3 May 2006. Therefore, the data for $\mathrm{H}_{2} \mathrm{~S}$ do not reveal a beneficial effect of the "A" Kraft mill shutdown on $\mathrm{H}_{2} \mathrm{~S}$ concentrations in ambient air. However, because more than $90 \%$ of the samples had undetectable $\mathrm{H}_{2} \mathrm{~S}$ concentrations, both before and after 3 May 2006, no reliable conclusion can be made about trends in $\mathrm{H}_{2} \mathrm{~S}$ concentrations.

For each TRS compound, Table 2 presents the average concentration before and after 3 May 2006, the percent change in average concentration resulting from the "A" kraft mill shutdown, and the confidence level that the difference in average concentrations is statistically different, as determined from a Student's $t$-test. Concentrations below the detection limit were arbitrarily assumed to be equal to half the AIS (i.e., $0.45 \mathrm{ppbv}$ for $\mathrm{H}_{2} \mathrm{~S}, 0.25 \mathrm{ppbv}$ for $\mathrm{CH}_{3} \mathrm{SH}$, and $0.046 \mathrm{ppbv}$ for DMS) for the purpose of calculating average concentrations. This assumption greatly affected the average concentrations of $\mathrm{H}_{2} \mathrm{~S}$ and $\mathrm{CH}_{3} \mathrm{SH}$ but had almost no effect on the average DMS and DMDS concentrations because 
DMS was rarely below the detection limit and DMDS was always above the detection limit.

Table 2: Average concentrations of TRS compounds in ambient air before and after the shutdown of the "A" Kraft mill.

\begin{tabular}{lcccc}
\hline & $\mathrm{H}_{2} \mathrm{~S}$ & $\mathrm{CH}_{3} \mathrm{SH}$ & DMS & DMDS \\
\hline Before 3 May 2006 & 0.51 & 0.41 & 1.49 & 0.202 \\
After 3 May 2006 & 0.65 & 0.29 & 0.45 & 0.086 \\
Percent of Change & $+27 \%$ & $-28 \%$ & $-70 \%$ & $-58 \%$ \\
Confidence level ( $t$-test) & $62 \%$ & $83 \%$ & $99.4 \%$ & $99.8 \%$ \\
\hline
\end{tabular}

DMS was the most abundant TRS compound before 3 May 2006 with an average concentration of 1.49 ppbv. The average DMS and DMDS concentrations in ambient air dropped respectively by $70 \%$ and $58 \%$ after the shutdown of the "A" Kraft mill. These drops are comparable to the declines in the emissions of these compounds from the plant (46\% for DMS and $72 \%$ for DMDS, see Table 1). Moreover, the results of the Student's $t$-test indicate that the shutdown of the "A" Kraft reduced the average concentrations of DMS and DMDS in ambient air with a confidence level larger than $99 \%$. The difference in numerical values between changes in emissions and changes in ambient air concentrations could be due to the fact that emissions fluctuate as a function of time. For example, the tall oil plant, which is a major contributor to DMS emissions (see Figure 1), only runs intermittently. Hence, the DMS concentration measured in ambient air is dependent on whether the tall oil plant is operating at the time of sampling. By contrast, the change in DMS emission rate is calculated on a yearly basis and accounts for the number of operating hours of each source.

The results of the Student's $t$-test for $\mathrm{CH}_{3} \mathrm{SH}$ indicate that the average concentration of this compound decreased after the shutdown of the "A" Kraft mill with a confidence level of $83 \%$. The average concentration of $\mathrm{CH}_{3} \mathrm{SH}$ decreased by $28 \%$, which is much less than the $85 \%$ decrease in $\mathrm{CH}_{3} \mathrm{SH}$ emissions from the plant (Table 1). However, because $\mathrm{CH}_{3} \mathrm{SH}$ was below the detection limit of $0.51 \mathrm{ppbv}$ in most of the ambient air samples collected after 3 May 2006, the actual decrease of the average $\mathrm{CH}_{3} \mathrm{SH}$ concentration may be underestimated. For example, if samples with undetectable $\mathrm{CH}_{3} \mathrm{SH}$ were assumed to contain no $\mathrm{CH}_{3} \mathrm{SH}$ rather than a concentration equal to half the AIS, the calculated reduction in the average $\mathrm{CH}_{3} \mathrm{SH}$ concentration would be $80 \%$, which is very close to the change in $\mathrm{CH}_{3} \mathrm{SH}$ emissions.

At first glance, the data for $\mathrm{H}_{2} \mathrm{~S}$ appears to indicate that the average concentration of this compound increased after the shutdown of the " $\mathrm{A}$ " $\mathrm{kraft}$ mill. However, the $t$-test shows that this would not be a valid conclusion since the confidence level for a change in the average $\mathrm{H}_{2} \mathrm{~S}$ concentration is only $62 \%$. This low confidence level reflects the fact that most of the $\mathrm{H}_{2} \mathrm{~S}$ concentrations were below the detection limit of 0.90 ppbv both before and after 3 May 2006. 
It is important to point out that the data do not rule out that the average $\mathrm{H}_{2} \mathrm{~S}$ concentration may have actually decreased after the shutdown of the " $\mathrm{A}$ " kraft mill (as could be logically expected given that the $\mathrm{H}_{2} \mathrm{~S}$ emissions from the Bowater Plant decreased by $91 \%$ ), but the detection limit for $\mathrm{H}_{2} \mathrm{~S}$ is too high to demonstrate this effect.

\section{Conclusions}

On 3 May 2006, the Bowater pulp and paper plant located in Thunder Bay shut down one of its two Kraft mills, thus reducing its overall air emissions of $\mathrm{H}_{2} \mathrm{~S}$, $\mathrm{CH}_{3} \mathrm{SH}$, DMS, and DMDS by $91,85,46$, and $72 \%$, respectively. Analyses of ambient air samples collected in the community surrounding the plant between 5 April and 14 September 2006 have shown that the concentrations of $\mathrm{CH}_{3} \mathrm{SH}$, DMS, and DMDS decreased by 28,70 , and $58 \%$, respectively after the shutdown date. The effect of the shutdown on $\mathrm{H}_{2} \mathrm{~S}$ concentrations in ambient air could not be ascertained because most of the samples had $\mathrm{H}_{2} \mathrm{~S}$ concentrations below the detection limit of $0.90 \mathrm{ppbv}$, both before and after the shutdown.

\section{Acknowledgement}

This research was supported by the Environmental Consortium of the University of Toronto Pulp and Paper Centre.

\section{References}

[1] Nagata, Y., Measurement of odor threshold by triangle odor bag method. Odor Measurement Review, Japan Ministry of the Environment, pp. 118-127, 2003

[2] Ontario Ministry of the Environment, Standards Development Branch, Summary of O. Reg. 419/05 Standards and Point of Impingement Guidelines \& Ambient Air Quality Criteria (AAQCs), December 2005.

[3] Bowater, 2005. Control Order Section 2.10, Selected targets for air compliance report, 22 September 2005. Available online at http://bowater.ca/content/media/media79..pdf

[4] Catalan, L.J.J., Optimization and calibration of a GC-PFPD-Cryogenic trapping system for the analysis of volatile sulfur compounds at trace levels in gases. Proc. of AWMA Air Quality Measurements, Methods and Technology Symposium, Durham, NC, 9-11 May 2006. Air \& Waste Management Association: Pittsburgh, PA, 2006.

[5] Catalan, L.J.J., Liang, V. \& Jia, C.Q., Comparison of various detection limit estimates for volatile sulphur compounds by gas chromatography with pulsed flame photometric detection. Journal of Chromatography A, 1136, pp. 89-98, 2006. 